\title{
A CLASSIFICATION METHOD FOR THE PRESENCE OF TIDAL SAND WAVES AND MAINTENANCE DREDGING DESIGN
}

\author{
Rick de Koning ${ }^{1}$, Jaap van Thiel de Vries $^{1}$ and Bas Borsje ${ }^{2}$
}

\begin{abstract}
The study into sand wave dynamics in South Channel commenced after large dune forms were observed in monitoring campaigns following the channel deepening project of the Port of Melbourne. The project involved deepening of the harbor berths and channels, but more importantly, it involved the deepening of South Channel in Port Phillip Bay. South Channel, the main shipping channel, crosses the bay over $\approx 20 \mathrm{~km}$. The growth of bedforms at various locations in South Channel now threatens to impede marine traffic. The dimensions and migration rate of the bedforms in the channel are remarkable, especially in the harsh flow conditions in the narrow channel. Therefore, the bedforms in South Channel cannot be given an obvious classification. In this paper it is shown that the bedforms in South Channel can be classified as a tidal sand wave type with a method that requires only insight in water depth, tidal flow velocity and grain size. Tidal sand waves are large-scale bedforms generated by recirculating flow cells that drive sediment to the top of a crest and are commonly observed on shallow coastal seas such as the North Sea. The bedform concern in the channel illustrates the necessity of an evaluation of the present, and alternative, channel maintenance strategies. A numerical model in Delft3D software is applied, along with a probabilistic calculation that combines insights from the simulations and survey data, to assess different maintenance strategies.
\end{abstract}

Keywords: tidal sand waves; classification; Delft3D; Melbourne; dredging; maintenance strategy

\section{INTRODUCTION}

In this paper a method is presented to classify observed bedforms as tidal sand waves based on relatively easy to obtain data about the local flow regime; water depth, tidal velocity and grain size diameter. Tidal sand waves are defined as bed forms that grow under the influence of residual tidal currents driving sediment particles to the crest of the sand wave (Hulscher, 1996). It is generally accepted that offshore tidal sand waves have wave heights of several meters, wavelengths of hundreds of meters and they migrate up to tens of meters per year (Van Santen et al., 2011). Tidal sand waves can cause failure of offshore construction sites when the troughs of migrating sand waves expose buried pipe-lines or cause scouring of offshore wind farm foundations. Also, sand waves can cause hindrance to vessel navigability (Borsje et al., 2013).

After a deepening campaign of the Melbourne shipping channel, regular monitoring of the channel bathymetry revealed fields of bed forms with high growth rate. The formation and growth of these bed forms in South Channel threatens to impede with marine traffic and thus requires the Port of Melbourne Corporation to apply an adequate channel maintenance strategy. The dynamics of the local bed forms are remarkable in terms of dimensions and growth rate, and therefore classical sand wave theory does not automatically apply to the South Channel bed forms.

The study aims for a better understanding of the dynamics of tidal sand waves in the context of managing and suppressing sand wave presence related to dredging and marine construction activities. To this end bathymetry and (numerical) flow data is analyzed alongside established sand wave literature to investigate if the South Channel bed forms can be classified as tidal sand waves. Maintenance strategy concepts are designed along two directions. One of them is to prevent the growth of tidal sand waves altogether, the other is to allow sand waves to grow but create a sufficiently large maintenance interval. A Delft3D numerical model is used to evaluate the different dredging strategies. This $2 \mathrm{DV}$ model can simulate tidal sand wave growth up to an equilibrium. Lastly, the characteristic growth curves from the numerical model are combined with measured data to enable a probabilistic approach predicting the maintenance interval per dredging strategy.

\footnotetext{
${ }_{1}$ Royal Boskalis Westminster N.V., Rosmolenweg 20, 3356 LK Papendrecht, The Netherlands

2 University of Twente, The Netherlands, Drienerlolaan 5, 7522 NB Enschede, The Netherlands 


\section{TIDAL SAND WAVES}

A seminal study into the formation of tidal bedforms was conducted by Hulscher (1996), and the study shows that tidal sand waves are formed by recirculating flow cells that drive sediment to a crest. This process is observed when time-averaging the oscillatory tide signal flowing over the bed perturbations, which reveals the residual flow. The flow cells are visible in Figure 1. Furthermore, the migration of tidal sand waves is explained by an asymmetry in the hydrodynamic forcing on the bedforms.

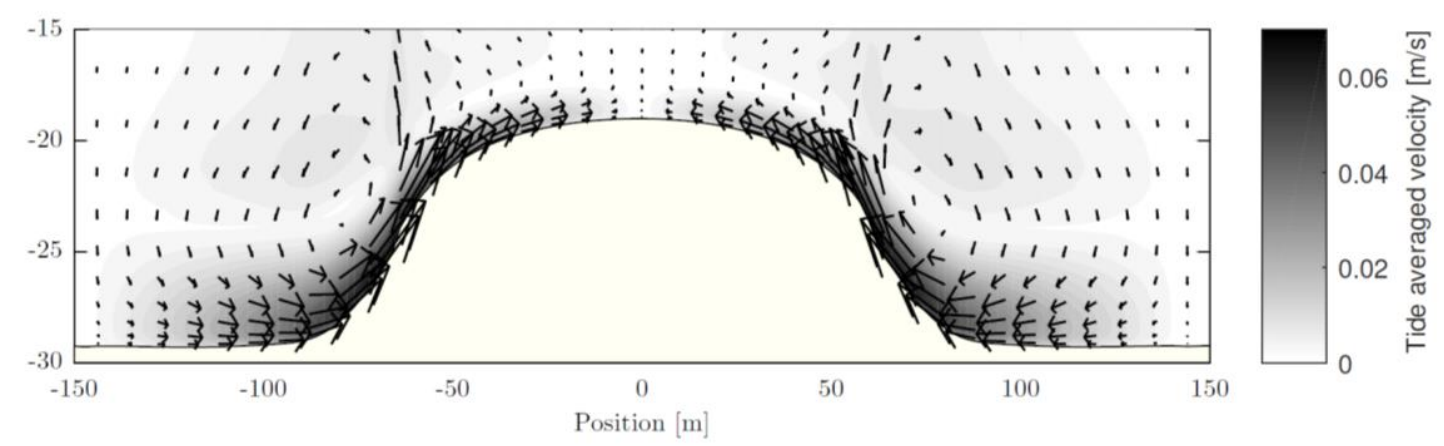

Figure 1. Illustration of the typical dimensions of an (offshore) tidal sand wave and of a time-averaged tide signal over a sand wave. This reveals recirculating flow cells on either side of the sand wave which drives sediment to the crest and causes the sand wave to grow. In nature, the influence of over-tides and currents will cause an inequality in the cells, resulting in a net migration of the sand waves. Figure from Van Gerwen et al. (2018)

The formation of sand waves is considered an instability mechanism of the dynamic system between flow and the erodible bed. To understand under what conditions the bed becomes unstable and sand waves start to grow, the growth rate of perturbations of different wave lengths under the influence of the tide is studied. If the tide-averaged residual flow causes a net sediment transport towards the crest, then a perturbation has a positive growth rate, hence the bed is unstable for that wavelength. Adding to that the effect of gravity which causes sediment to move more difficult up-slope than downslope results in a preferred wavelength for a system, which is called the Fastest Growing Mode or $\mathrm{L}_{\mathrm{FGM}}$ (Borsje et al., 2009).

The (mathematical) stability analysis for tidal sand waves by Hulscher (1996) (and extended by Borsje et al. (2009)) is shown in Figure 2 (left). The figure shows a diagram with the three major forcing parameters for tidal sand wave formation, namely the water depth, the velocity amplitude of the dominant tidal component $\left(\mathrm{M}_{2}\right)$ and the local grain size diameter $\left(\mathrm{d}_{50}\right)$.

In Borsje et al. (2014) critical conditions for sand wave formation are formulated related to the dominant mode of sediment transport. Namely, in the field no sand waves are found where suspended sediment transport is the main mode of transport. The dominant mode of transport is indicated with the Rouse number, which is expressed in the same parameters. Therefore, an upper boundary can be added to the sand wave regime in terms of the Rouse number. This adaptation is shown in Figure 2 (right) for a d $_{50}$ of $500 \mu \mathrm{m}$ where the bottom line $(\mathrm{P}=2.5)$ shows the onset of the suspended sediment transport in a flow and the top line $(\mathrm{P}=2.0)$ indicates the boundary value for which tidal sand waves are found in nature according to Borsje et al (2014). 

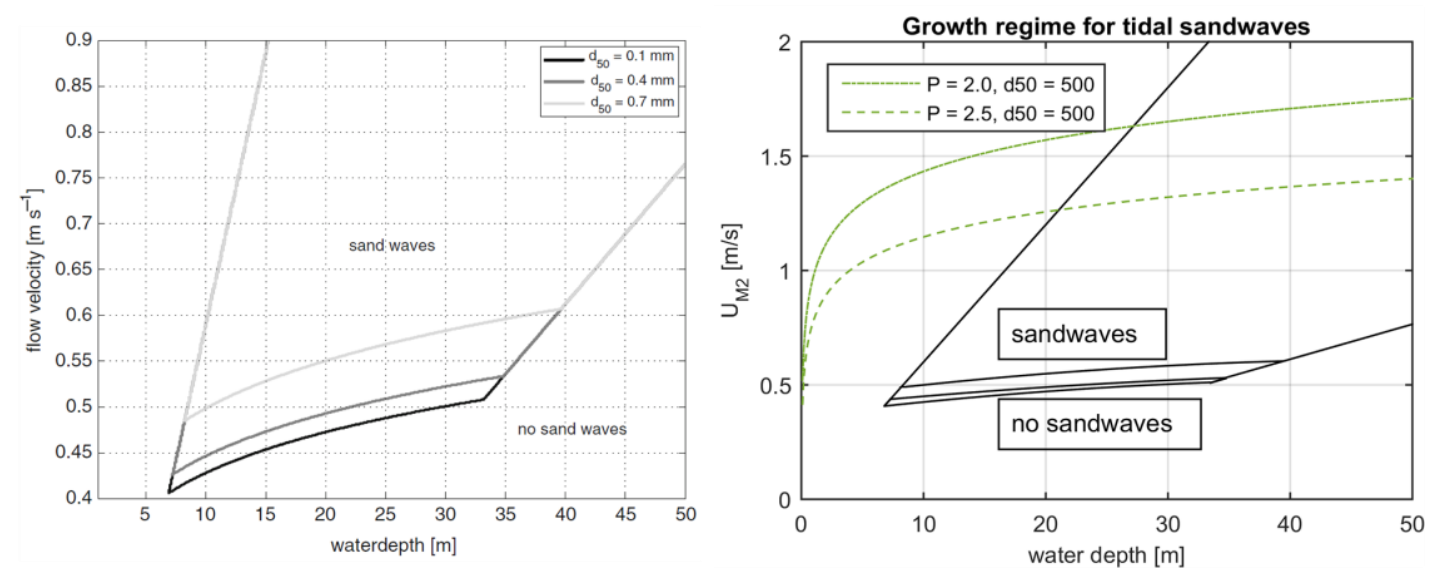

Figure 2. Left shows the result of the (mathematical) instability analysis of the tidal sand wave regime (Hulscher, 1996). The growth regime is defined by the three major variables: the water depth, the velocity amplitude of the M2 tide and the nominal grain size diameter. On the right an upper boundary to the regime is added based on the Rouse number, which indicates the transition between bed load sediment transport and suspended sediment transport (for increasing velocity).

\section{PORT PHILLIP BAY AND SOUTH CHANNEL}

Port Phillip Bay is a basin connected through a gap to the ocean. Large amounts of water flow in and out of the bay daily which make it a dynamically active area. The city of Melbourne lies in the north of the area where the Yarra river enters the bay. The south of the bay, where the influence of the tidal flows and swell waves is the largest, is the most dynamically active in terms of sediment transport. The South of the bay is depicted in Figure 3 and its main features are highlighted, with the shipping channel (South Channel) clearly visible from east to west.

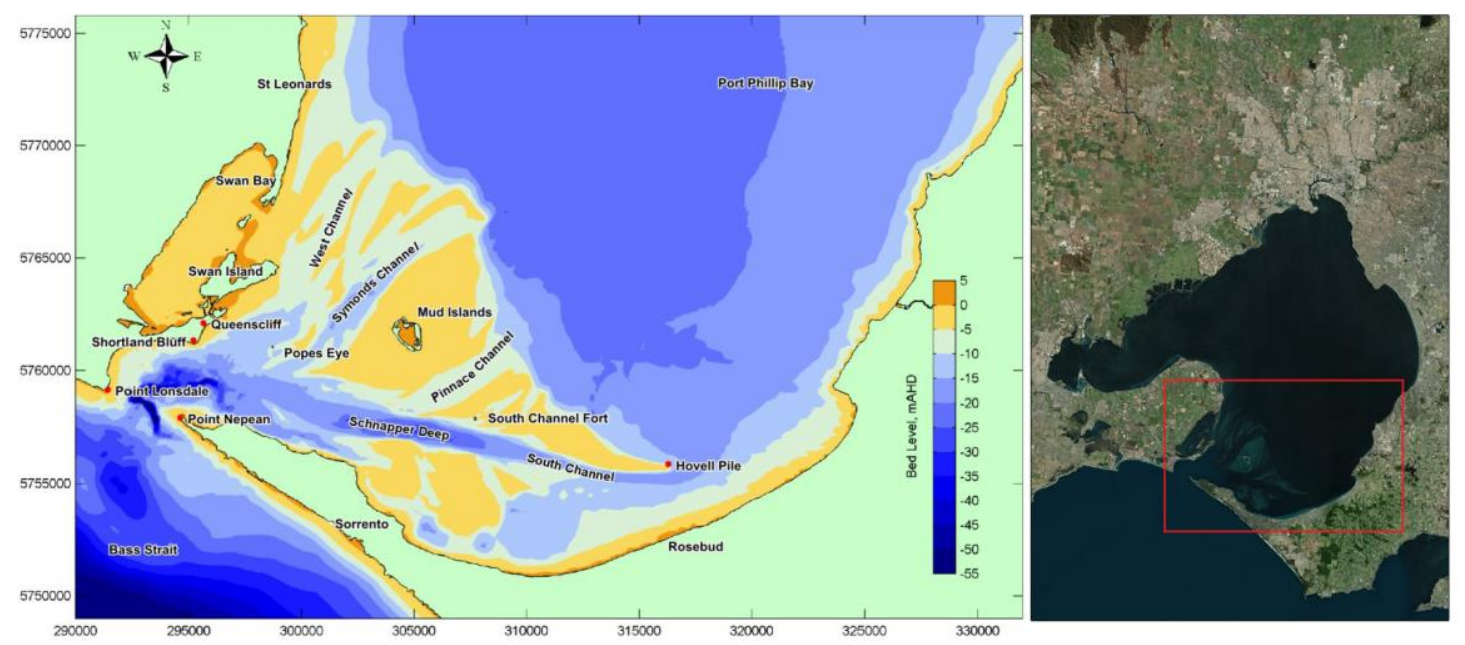

Figure 3. Overview of Port Phillip Bay, which is the naval entrance to the city of Melbourne. The bay has a narrow entrance where an underwater canyon has formed. The shipping channel, called South Channel, transverses the bay from west to east as illustrated on the left. The channel is $10-20 \mathrm{~m}$ deep and has a sandy bed. The shallow sandy features on either side of the channel are relic features and are relatively stable (Cardno 2011).

In South Channel the water depth ranges from $0-5 \mathrm{~m}$ on the muddy shallows to a maintained depth of approximately $-15 \mathrm{~m}$ in the shipping channel. The tide is characterized as semi-diurnal with a diurnal inequality. This means that there are two tidal cycles every day, with one high-water higher than the other high-water, and low-water vice versa. This effect is enlarged inside the bay due to the restricted entrance and shallow water depths. The tidal range in the channel is approximately $1 \mathrm{~m}$. Due to the shallow water depths, a limited fetch from the North and the restricted entrance, wave action in South Channel is relatively small and its influence on local sediment transport is negligible (Cardno, 2011). 
The bottom of the channel is characterized as a mobile sea bed with most grain size samples falling between $250 \mu \mathrm{m}$ and $450 \mu \mathrm{m}$.

The sand waves are observed in five patches along the shipping channel with a median wave height of $1.0 \mathrm{~m}$ to $1.9 \mathrm{~m}$ and median wavelength between $35 \mathrm{~m}$ and $70 \mathrm{~m}$.

\section{TIDAL SAND WAVE CLASSIFICATION BASED ON DEPTH AND FLOW DATA}

In Figure 4 flow data retrieved from a numerical model of the five sand wave areas in South Channel is plotted on the regime for sand wave growth from literature (see Figure 2). In contrary to looking solely at the physical dimensions of the sand waves, this method tests if the flow regime of the five patches in South Channel is in accordance to the tidal sand wave regime. The data is extracted from a Delft3D study performed by Cardno (2011) and it only outputs (depth-averaged) hydrodynamics of the area, thus no morphological changes are simulated.

The data for the depth-averaged velocity and water depth for the different survey areas is extracted and plotted on the sand wave regime, see Figure 4. This graph points out at what locations tidal sand wave growth is expected and that result is compared with the actual observations of bedforms in South Channel.

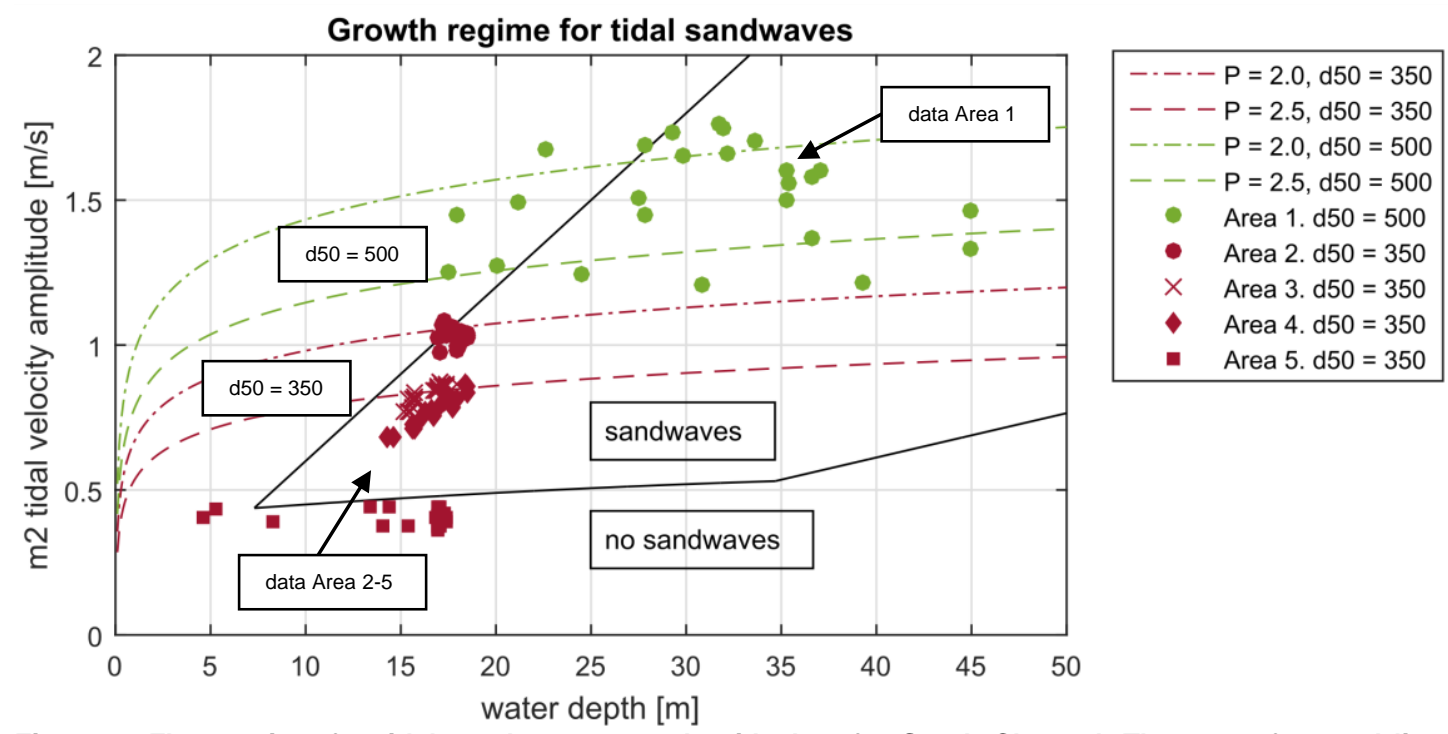

Figure 4. Flow regime for tidal sand wave growth with data for South Channel. The sets of curved lines represent different values of the Rouse number for different grain sizes. For every set, the bottom line shows the onset of suspended load transport and the top line shows the boundary above which tidal sand waves are not observed in nature. The color of the lines stands for the considered $d_{50}$, which then coincides with the $d_{50}$ in data-points of the same color.

The data plotted onto the diagram appears to agree well to the sand wave regime. Area 3 and 4 lie firmly in the regime, predicting the growth of tidal sand waves, whereas the data for Area 5 lies outside the sand wave regime. Both findings are in agreement with the observations in South Channel. For Area 2 the diagram predicts that the local flow conditions are on the edge of the tidal sand wave regime, which makes it possible that other kinds of bedforms are apparent in Area 2. The flow data for Area 1 is highly irregular and almost all the data points lie in the suspended sediment transport regime or outside of the tidal sand wave regime, making it highly unlikely for tidal sand waves to grow at that location. This is also in agreement with the observations in South Channel.

The same methodology is extended to predict what areas in South Channel (as a whole) are sensitive to tidal sand wave growth. To produce a prediction for the complete channel an extended set of flow data is used, shown in Figure 5. Subsequently, this data is interpolated to obtain a $25 \times 25 \mathrm{~m}$ dataset for the channel area. Again, every data point holds an entry for water depth and depth-averaged velocity and the combination is tested against the parameter space for sand wave growth as in Figure 2.

Aside from the fact that the interpolation is a simplification of reality, it is also assumed that the complete domain has a grain size of $350 \mu \mathrm{m}$. This implies that the upper boundary of the sand wave parameter space for this procedure is defined as the $\mathrm{P}_{2.0}$-line for $350 \mu \mathrm{m}$. The result of the prediction is shown in Figure 6. 


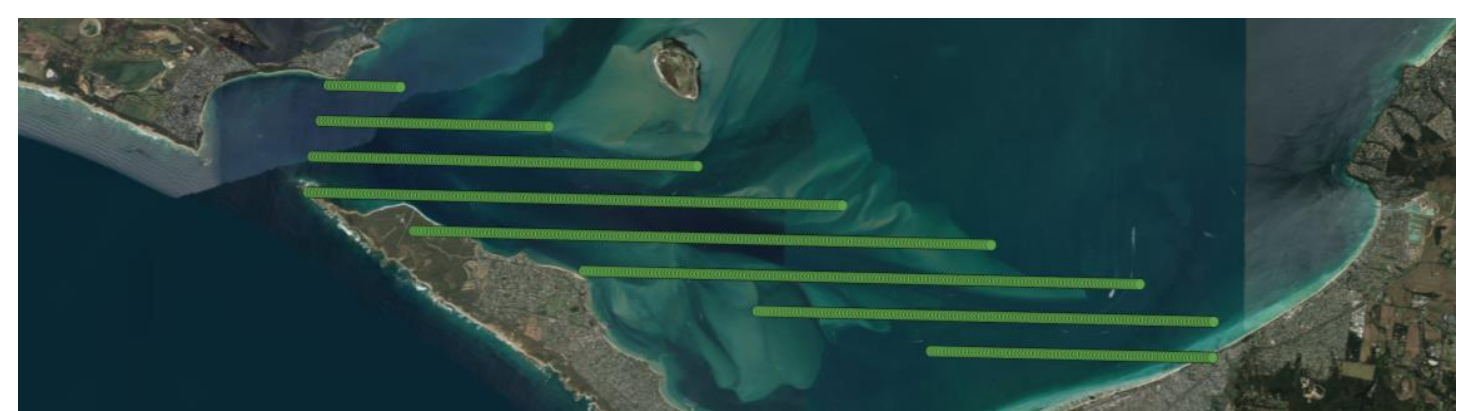

Figure 5. Output locations for Delft3D generated hydrodynamic data for tidal sand wave prediction in South Channel. Every data point provides a value for the water depth and M2 tidal velocity.

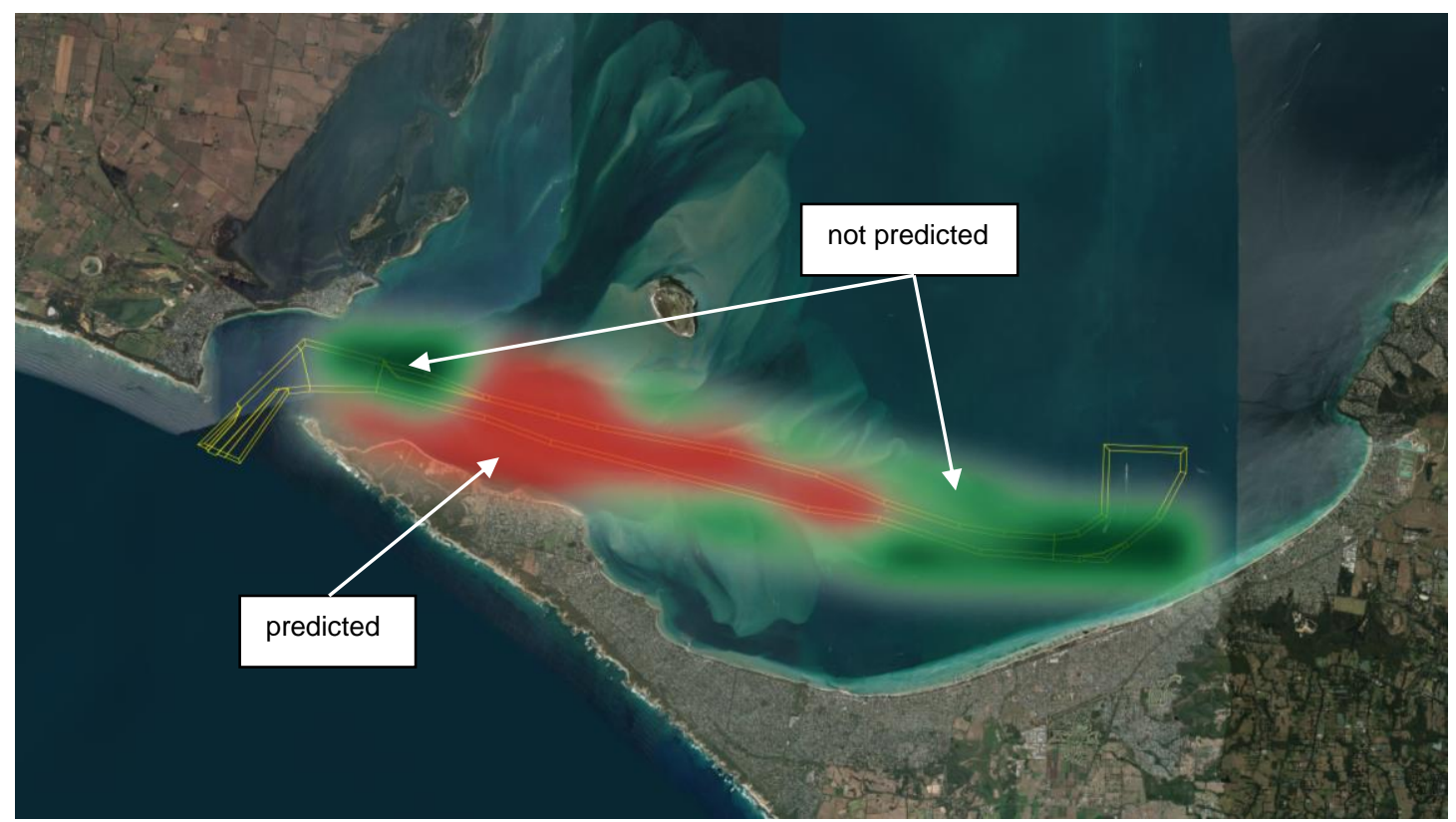

Figure 6. Result of the areas that are predicted to be susceptible to tidal sand wave growth in red (patch in the center) and the areas predicted to be outside of the tidal sand wave regime in green (right and top-left). A positive match between observation of sand waves in the bathymetry and prediction with this method is found for $74 \%$ of the area.

The skill of the latter method to predict tidal sand wave growth is expanded into the whole South Channel by interpolating the flow data for several locations in the channel. The interpolation naturally introduces an error into the prediction procedure, but the results when using the same diagram to decide where and where not tidal sand wave growth is expected is remarkable. A positive match between observation and prediction is found for $74 \%$ of the area.

It is concluded that the bedforms in the different survey areas in South Channel are rightfully classified as tidal sand waves. Additionally, it is reasoned that the sand waves originate inside the channel which influences the maintenance design choices.

\section{DREDGING STRATEGY DESIGN}

\section{Design Directions}

Two approaches for dredging maintenance design are considered, namely 'mitigation' and 'prevention'. A mitigating solution is defined as a dredging campaign that removes the sand waves but allows them to grow back over an acceptable period. A preventing solution creates an environment in which future sand wave maintenance is unnecessary.

For a design that prevents the regrowth of sand waves indefinitely, either the course of the channel or the dimensions of the channel need to be altered severely to create non-favorable conditions for tidal sand wave growth. It is reasoned that this type of solution is not economically sound and will have a 
large environmental impact in this case, therefore the focus is on solutions that deal with the sand wave fields locally and create an acceptable maintenance interval (mitigation).

Several growth-mitigating solutions are investigated, illustrated in Figure 7. The current dredging strategy, dredging to the required navigation depth, removes mostly the peaks of the sand waves and leaves part of the sand waves intact ('Peak Removal'). This method is compared to the removal of the sand wave field down to trough level ('Removal') and to dredging deeper than trough level ('Over depth'). 'Case I LT' is the reference case investigated in the model, in which the sand wave field grows from the average depth $(-17.5 \mathrm{~m})$ and from an (almost) flat bed up to an equilibrium. 'Case I LT' can also be considered as a dredging strategy where the troughs of the sand wave field are filled in with sand from the peaks, returning the field to the average depth or 'smoothing' the field.

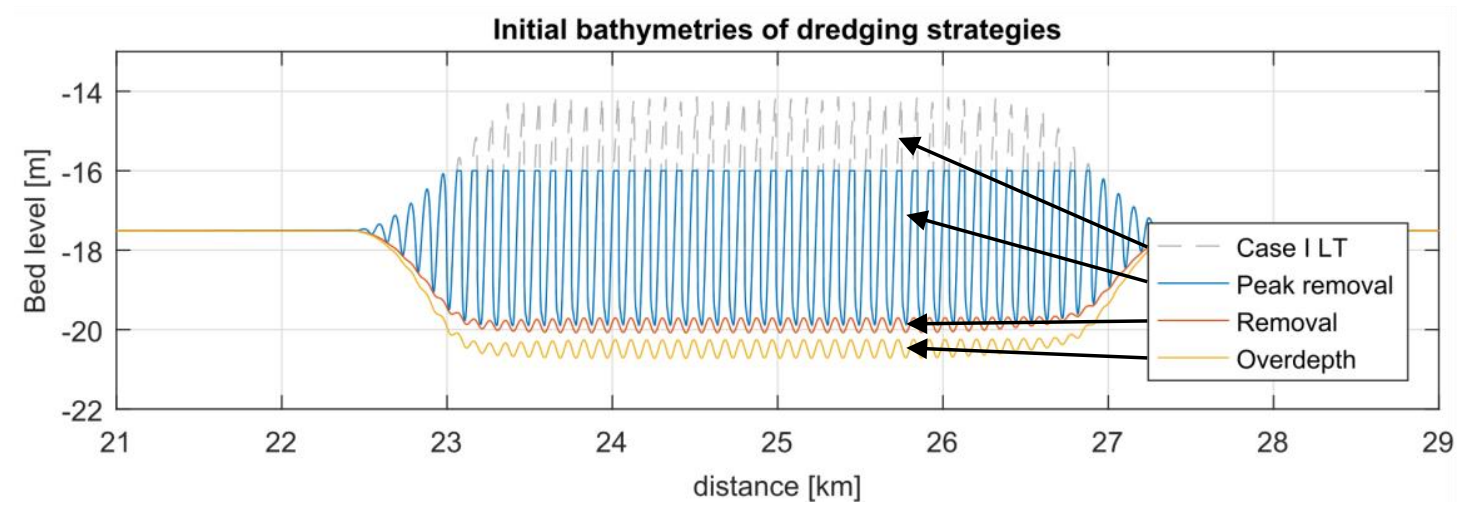

Figure 7. Illustration of the different dredging strategies evaluated in this research, aimed at mitigating sand wave growth. 'Peak removal' leaves the wave field largely intact as it is motivated by a fixed maintained depth. The other strategies are aimed at removing the wave field structure or removing the wave field entirely.

\section{Numerical Modelling}

A numerical model (Delft3D) is used to simulate sand wave growth. Morphological interactions are included and the model is set up in 2DV space. This model was developed by Borsje et al. $(2013,2014)$ and later by Van Gerwen et al. (2018) and it is the first model that can simulate tidal sand waves up to a stable and realistic equilibrium.

The numerical domain is set up in 2DV space, meaning only variations of the flow and the bed in the $x$ and $z$ direction are considered. The calculation grid has a variable resolution in both the horizontal and the vertical direction. The horizontal domain has a total length of $50 \mathrm{~km}$ with a grid resolution of $\pm 1500 \mathrm{~m}$ at the boundaries and $2 \mathrm{~m}$ in the center, where the sand wave field is imposed. Moreover, this center region has a length of $2 \mathrm{~km}$. In the vertical, the layers have a higher density towards the bed. Both bedload and suspended load transport are included in the simulation. Finally, to simulate the long-term development of the sand wave field, a morphological acceleration factor (MORFAC) of 500 is used.

The simulation of a sand wave field consists of an organization phase and a growth phase. In the first phase the growth rate of small initial perturbations with different wavelengths are calculated under

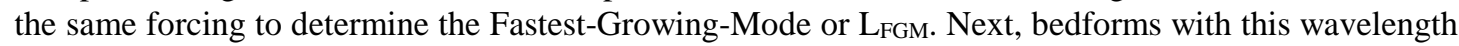
( $\left.\mathrm{L}_{\mathrm{FGM}}\right)$ and with a small amplitude, $1 \%$ of the water depth, are installed as the initial bed in the model. The long-term calculation then considers the growth of these perturbations up to an equilibrium.

Site-specific adaptation of the model for South Channel conditions is implemented by changing the water depth, tidal current strength and sediment grain size in the model. With a reasonable adaptation of the bed roughness, a $\mathrm{L}_{\mathrm{FGM}}$ of $93 \mathrm{~m}$ is found which is an adequate representation of the sand wave lengths found in South Channel. The simulated crest and trough development of the dredging strategies introduced in Figure 7 are presented in Figure 8. 


\section{COASTAL ENGINEERING 2018}

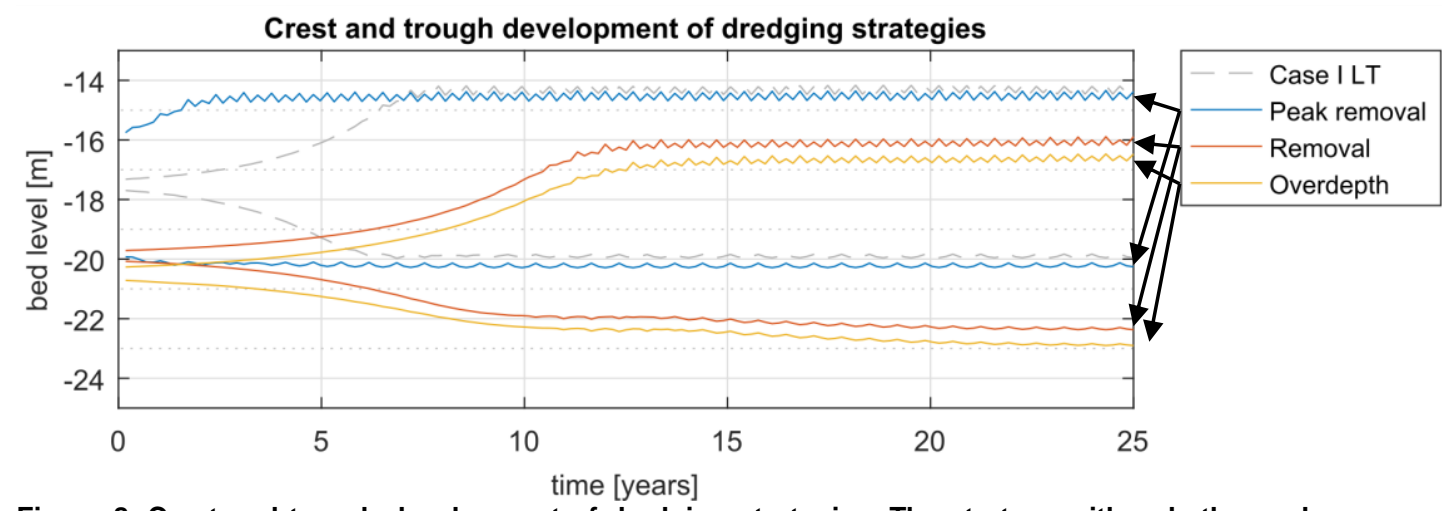

Figure 8. Crest and trough development of dredging strategies. The strategy with only the peaks removed grows back to an equilibrium within two years, compared to the other strategies where it takes seven to fourteen years. The equilibrium wave height obtained for the different strategies is comparable, but for the strategies that start with a deeper average bed level the wave crest levels also lie deeper.

As expected, the peak removal strategy is the fastest to grow back to an equilibrium with a $\mathrm{T}_{\mathrm{EQ}}$ of 2 years. In comparison, $\mathrm{T}_{\mathrm{EQ}}$ is approximately 14 years for the 'removal' and 'over depth' strategy. The high-spot for the peak removal strategy is approximately equal to the original run Case I LT (or 'smoothing'), while the high-spot for the other strategies lies significantly deeper. It is observed that the trough of the 'removal' and 'over depth' strategy also obtain a deeper equilibrium than Case I LT. It is reasoned that this is a result of the absence of a sediment influx on the model boundaries, which causes that local sediment is used for the sand wave growth. The equilibrium wave height is approximately the same for the different strategies.

The simulated wave height is approximately 2 to 3 times the height of the wave height observed in the field data. While this is a considerable overestimation of the local wave height, this is best explained as the result of the schematization of the model over reality. The numerical model uses a 2D domain with a single tidal component and a single grain diameter, whereas South Channel lies in a bay with complex three-dimensional flow and sediment transport patterns. Moreover, the sediment transport rates in the model have not been calibrated with local values, whereas tidal sand wave development is highly sensitive to the bedload and suspended load transport magnitudes. The 'wiggle' visible in the model output is likely a result of the combination of the applied MORFAC and the model output writing frequency.

\section{Probabilistic Method}

The results of the simulations point out that the return time to equilibrium height of the sand waves in the peak removal strategy is a factor 7 faster than for the other strategies. Though the simulation results provide interesting insights, they cannot be applied straight forward to assess the navigability of South Channel for the various dredging strategies. That is because the simulated wave height is approximately 2 to 3 times the height of the wave height observed in the field data. Furthermore, the bed level in South channel (in the absence of sand waves) cannot be considered flat as assumed in the simulations. Lastly, the available bed surveys reveal a broad range of sand wave heights (and lengths), in contrast to the model results with a single wave height and wave length.

The aim here is to combine survey data and the numerical simulation results to provide a better insight in the probability of breaching the maintained depth in South Channel for the strategies evaluated in previous sections. To this end, a probabilistic approach is considered.

In the probabilistic approach a limit state function is constructed in the form of $\mathrm{Z}=\mathrm{R}-\mathrm{S}$, where $\mathrm{R}$ stands for 'resistance' and the S stands for 'solicitation'. The resistance of the system is the maintained depth. The solicitation (or forcing) of the system is the sum of the bed level and a sand wave amplitude, which both have a stochastic distribution based on available measurements. In case bed level plus sand wave amplitude exceed the maintained depth, the system has 'failed'. The probability of failure can be calculated through a Monte Carlo Simulation in which the distributions of bed level and sand wave height (constructed from measurements) are sampled. The total probability of failure is calculated by $\mathrm{P}_{f}=N_{\mathrm{Z}<0} / N_{\text {total }}$. The probability of failure $(\mathrm{Z}<0)$ will change in the course of time after dredging and depends on the timescale of sand wave recovery to equilibrium height, which is adopted from the numerical simulations. The basis for the probabilistic calculation is illustrated in Figure 9. 


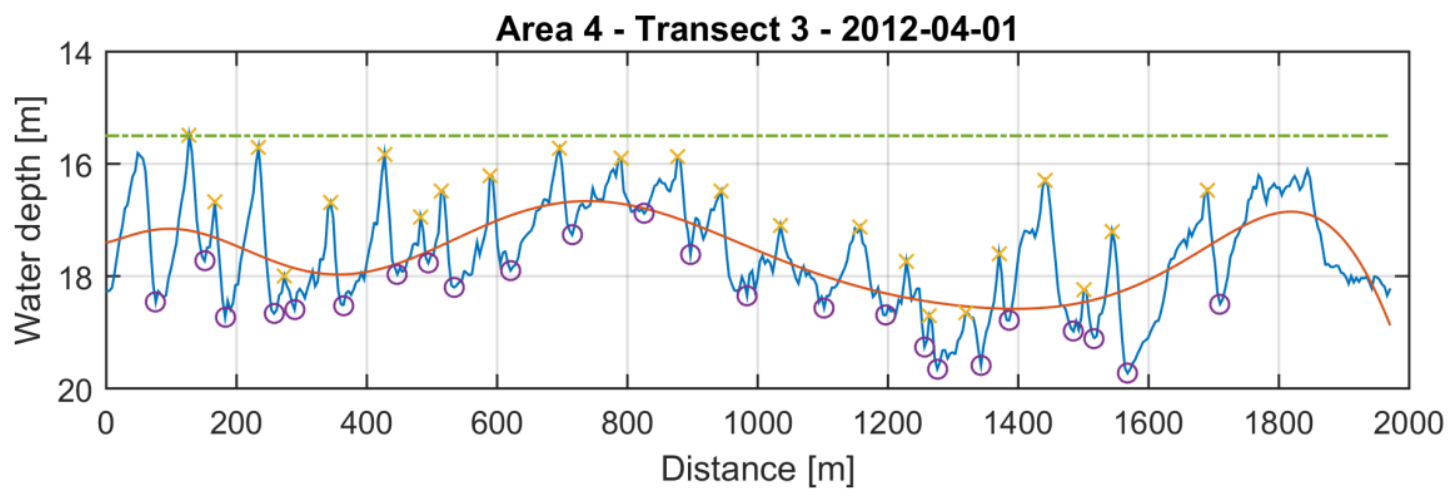

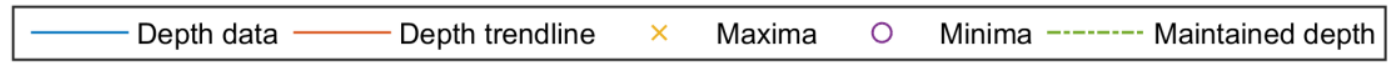

Figure 9. Plot of measured bed level data in South Channel. The different elements of the probabilistic calculation are illustrated. The sand waves and the bed level both have their own stochastic distribution, whereas the maintained depth of $-15.5 \mathrm{~m}$ represents the 'resistance' of the system. When the average bed plus sand wave amplitude breach the maintained depth, the system fails.

To achieve a cost-efficient dredging strategy the evolution of the probability of breaching can be considered as function of time after dredging. However, a stochastic distribution of the sand wave amplitudes in time is not available from measurements and requires scaling the distributions of sand wave amplitude with the temporal results from the numerical model.

The basis for the time-dependent scaling is that a smaller sand wave grows quicker to its equilibrium than a larger sand wave (and vice versa). For brevity a simple relation is applied that scales with the sand wave volume, which is proportional to the sand wave height squared. With this approach, for every sand wave in the measured data a synthetic growth curve is created, with unique equilibrium heights and equilibrium growth times. This is illustrated in Figure 10.

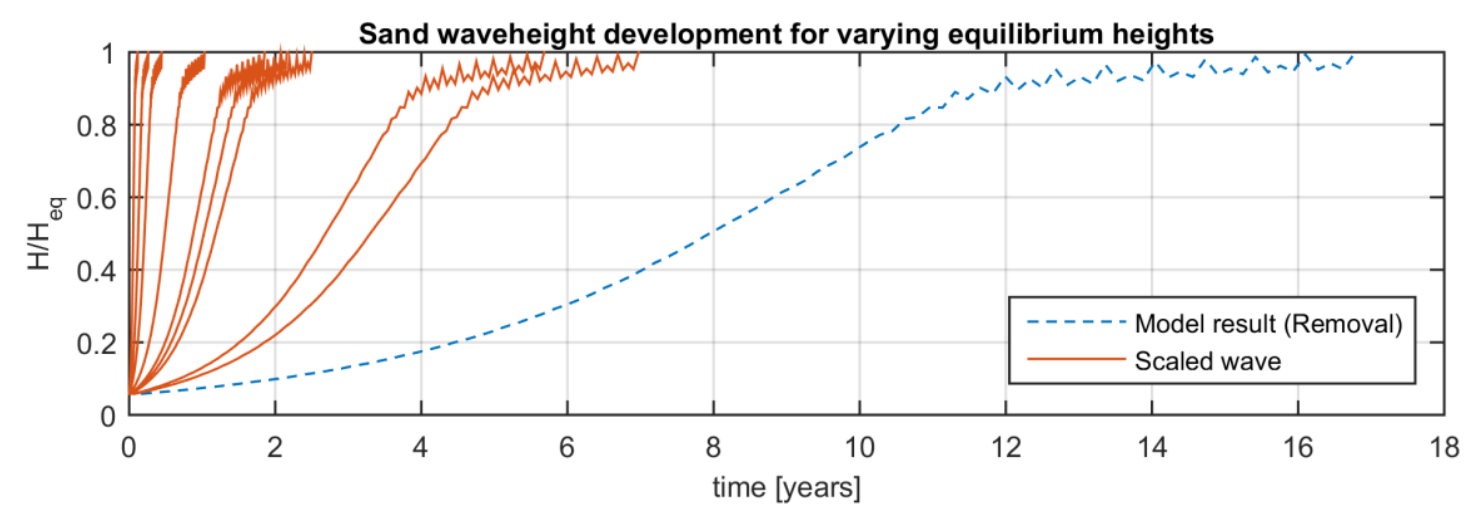

Figure 10. Synthetic growth curves for measured sand waves with different wave heights in South Channel. The growth of the sand waves is scaled from the numerical model results, on the basis that a smaller sand wave grows quicker to its equilibrium height than a larger wave.

Monte Carlo simulations are performed at different time intervals after a dredging strategy has been implemented. The probability of failure is evaluated at $t_{H}=0.1,0.5,1,2,4,6,8$ and 10 years. The probabilistic calculations are conducted for all dredging strategies. Since four dredging strategies and eight time-steps are considered, a total of 32 calculations are performed. The stochastic variables for the bed level and the sand wave amplitude are implemented in the calculation as a discrete distribution with 25 bins and the corresponding probabilities. Every calculation results in a probability of failure $\left(\mathrm{P}_{\mathrm{f}}\right)$, and the results are illustrated in Figure 11.

Over the course of the available surveys (2012-2016) on average 7.7\% of the wave crests are found above $-15.5 \mathrm{~m}$. Non-surprisingly, this is also the value that Figure 11 gravitates towards. The study by PoMC (2014) reports on crests breaching the maintained depth line as early as 6 months after dredging. In Figure 11 the risk for a breach after peak removal rises from $2.5 \%$ to $7 \%$ in the first year, which 
underlines that breaches are expected very early on. After smoothing the bed, a similar probability of failure $>7 \%$, i.e. more than 7 peaks out of 100 are shallower than $-15.5 \mathrm{~m}$, is found after 4 years. For the remaining strategies, 'removal' and 'over depth', the figure shows that the probability of breaching over the course of 10 years is close to 0 .

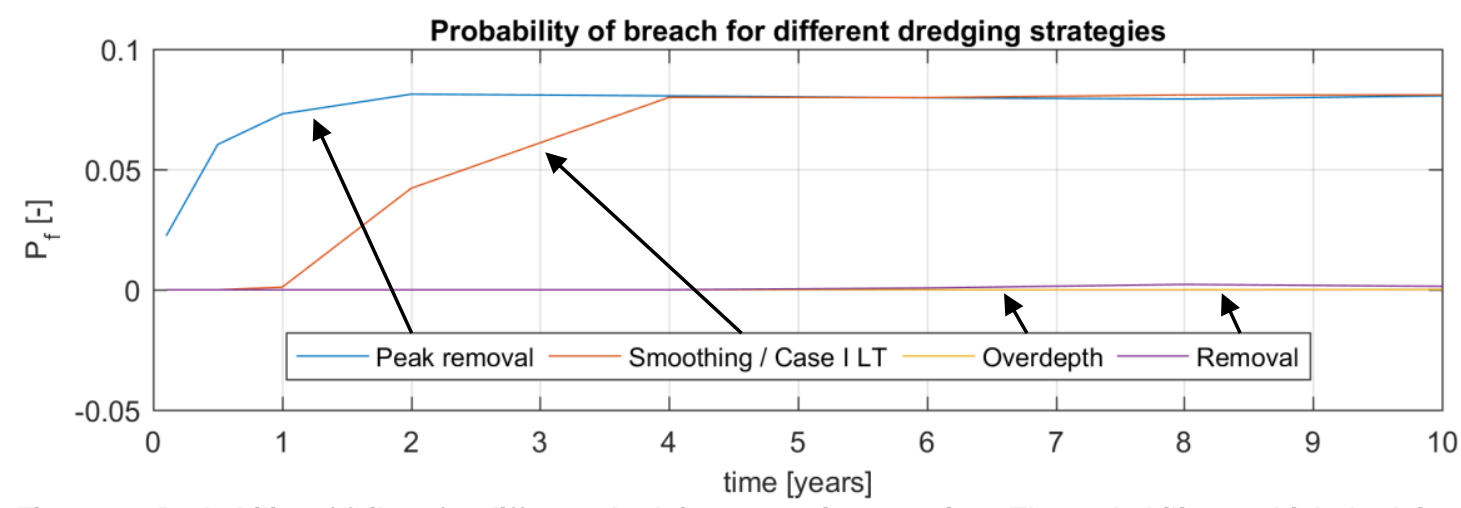

Figure 11. Probability of failure for different dredging strategies over time. The probability at which dredging is required in the channel is $\sim 7 \%$ (or $P=0.07$ ). This probability is reached within the first year for the 'peak removal' strategy, which is a good representation of the situation observed in the channel. The 'smoothing' strategy significantly enlengthens the dredging maintenance interval and the probability of breaching for the other two strategies is still 0 after 10 years.

\section{MAIN FINDINGS AND OUTLOOK}

To determine if bed forms in South Channel can be classified as tidal sand waves, both the physical dimensions and the hydraulic environment of the bedforms are studied. Hulscher (1996) defined a spectrum of hydrodynamics in which tidal sand waves can grow. From findings by Borsje et al. (2014) an upper boundary to this spectrum is added, based on the transition from bedload to suspended load sediment transport. Subsequently, a 74\% agreement is found between predicted and actual bedform presence in the channel, see Figure 6. The results also indicate local generation of sand waves, which defines the focus point of the maintenance strategy design. The dredging strategies considered aim for an optimization of the maintenance interval.

The strategies are the removal of the sand wave field and the removal of the sand wave field plus extra dredging. Additionally, a strategy is considered in which the sand of the wave peaks is removed and placed in the troughs, effectively smoothing the bed and not removing a net amount of sediment from the system. The reference dredging strategy is where the peaks of the sand waves are removed, but the wave field shape stays largely intact.

A probabilistic approach shows similar regrowth for the simulated and measured sand waves for the 'peak removal' removal. Smoothing the bed may increase the maintenance interval by 3 years, while removing more sand from the system increases that period substantially.

The paper provides the knowledge, methods and tools required for the classification of bed forms as tidal sand waves using only low-detail hydrodynamic data. This also shows the potential as a prediction tool for sand wave presence. Additionally, the numerical study enables the design of dredging strategies that require less volume of material moved and are less intrusive on the environment. Including sand wave migration into the method will provide additional design optimization potential. 


\section{REFERENCES}

Borsje, B. W., Hulscher, S. J. M. H., Herman, P. M., \& De Vries, M. B. (2009). On the parameterization of biological influences on offshore sand wave dynamics. Ocean dynamics, 659-670.

Borsje, B. W., Roos, P. C., Kranenburg, W. M., \& Hulscher, S. J. M. H. (2013). Modeling tidal sand wave formation in a numerical shallow water model: The role of turbulence formulation. Continental shelf research, 17--27.

Borsje, B. W., Kranenburg, W., Roos, P., Matthieu, J., \& Hulscher, S. J. M. H. (2014). The role of suspended load transport in the occurrence of tidal sand waves. Journal of Geophysical Research: Earth Surface, 119, 701--716.

Cardno. (2011). Sediment Transport Modelling - Great Sands, Port Phillip. Melbourne.

Hulscher, S. J. M. H.(1996). Tidal-induced large-scale regular bed form patterns in a three-dimensional shallow water model. Journal of Geophysical Research: Oceans, 20727-20744.

PoMC. (2014). Sand Wave Assessment - South Channel Accretion Study.

van Gerwen, W., Borsje, B. W., Damveld, J. H., \& Hulscher, S. J. M. H.(2018). Modelling the effect of suspended load transport and tidal asymmetry on the equilibrium tidal sand wave height. Coastal Engineering, 136, 56--64.

Van Santen, R., De Swart, H., \& Van Dijk, T. (2011). Sensitivity of tidal sand wavelength to environmental parameters: A combined data analysis and modelling approach. Continental Shelf Research, 966--978. 